\title{
Review of the Fannia postica-group Chillcott, 196I of the genus Fannia Robineau-Desvoidy, 1830, with description of two new species from the Palearctic and Oriental regions (Diptera, Fanniidae)
}

\author{
Ming-fu Wang', Wei Li², Wei-bing Zhu ${ }^{3}$, Dong Zhang ${ }^{4}$ \\ I Institute of Entomology, Shenyang Normal University, Shenyang, 110034, P.R. China 2 College of Biological \\ Sciences and Biotechnology, Beijing Forestry University, Beijing, 100083, P.R. China 3 Shanghai Entomological \\ Museum, Chinese Academy of Sciences, Shanghai, 200032, P.R. China 4 School of Nature Conservation, Beijing \\ Forestry University, Beijing 100083, P.R. China \\ Corresponding authors: Ming-fu Wang (wangmingfu403@163.com); Dong Zhang (ernest8445@163.com)
}

Academic editor: P. Cerretti | Received 31 January 2016 | Accepted 10 May 2016 | Published 14 June 2016

http://zoobank.org/2ADA598C-CEC1-4EFF-8AD0-7431B9E17B36

Citation: Wang M-f, Li W,Zhu W-b, Zhang D (2016) Review of the Fannia postica-group Chillcott, 1961 of the genus Fannia Robineau-Desvoidy, 1830, with description of two new species from the Palearctic and Oriental regions (Diptera, Fanniidae). ZooKeys 598: 113-128. doi: 10.3897/zookeys.598.7983

\begin{abstract}
A total of 17 species of the Fannia postica-group Chillcott, 1961 from the Palearctic and Oriental regions are reviewed herein, 2 of which are described from China as new: Fannia ningxiaensis Wang \& Zhang, sp. n. and Fannia subaethiops Wang \& Zhu, sp. n.. Fannia labidocerca Feng \& Xue, 2006, originally placed in F. serena-group Chillcott, 1961, is moved to the postica-group and re-described. An identification key to the males of known species from these regions is provided.
\end{abstract}

\section{Keywords}

Species transference, F. serena-group, identification key, new Chinese species

Copyright Ming-fu Wang et al. This is an open access article distributed under the terms of the Creative Commons Attribution License (CC BY 4.0), which permits unrestricted use, distribution, and reproduction in any medium, provided the original author and source are credited. 


\section{Introduction}

The Fannia postica-group was established in the genus Fannia Robineau-Desvoidy, 1830 by Chillcott (1961). Species of this group are classified under two subgroups, the F. postica-subgroup and the F. spathiophora-subgroup (Chillcott 1961). The group is currently composed of approximately 25 known species worldwide (including the species added in this paper), most of which are distributed in the Holarctic Region, with a minority of species in the Oriental Region (Wang et al. 2011). They are: $F$. postica-subgroup: F. brevicauda Chillcott, $F$. discoculea Xue, $F$. enigmata Chillcott, $F$. flavibasis (Stein), F. labidocerca Feng \& Xue, F. multisetosa Chillcott, F. postica (Stein), F. ringdahlana Collin, F. sequoiae Chillcott; F. spathiophora-subgroup: F. aethiops Malloch, F. ardua Nishida, F. bigelowi Chillcott, F. brooksi Chillcott, F. coculea Nishida, F. gotlandica Ringdahl, F. ningxiaensis Wang \& Zhang, sp. n., F. nudifemorata Wang \& Zhang, F. scyphocerca Chillcott, F. slovaca Gregor \& Rozkošný, F. spathiophora Malloch, F. stigi Rognes, F. subaethiops Wang \& Zhu, sp. n., F. tundrarum Chillcott, F. umbratica Collin, F. umbrosa (Stein).

At the end of the nineteenth century, Stein (1895) described the Palearctic and Oriental species, F. postica (Stein). Since the beginning of the twentieth century, a number of papers and monographs studying the European species of $F$. postica-group have been published (Ringdahl 1926, Collin 1939, Hennig 1955, D’Assis-Fonseca 1968, Rognes 1982, Gregor and Rozkošný 2005). Pont (1986) reviewed the Palearctic fanniids, including species of the $F$. postica-group. Rozkošny et al. (1997) treated species of the Family Fanniidae from Europe and added nine species to the F. postica-group.

Asian species of the F. postica-group were mainly reported on by Nishida (1975, 1976), Pont (1977), Fan (1992), Xue and Wang (1998), Xue et al. (2001), Wang and Xue (2002) and Wu and Wang (2002). Wang et al. (2011) listed 22 known species of this group worldwide, recorded nine species of the postica-group from China and, based on the definition of the group by Chillcott (1961), summarized features of the male habitus and terminalia that distinguish it from other Fanniidae.

The biological characteristics of these species have never been fully studied. The study of specimens in our entomological collections has revealed that the majority of species in the group occur in wooded or shrubby habitats. According to Rozkošný et al. (1997), the immature stages of some species, such as F. umbrosa (Stein), live in birds' nests or in sap flowing out of rotholes in trees. The larvae of F. postica (Stein) and $F$. umbrosa (Stein) feed on humic substances, whereas the larvae of $F$. postica (Stein) also develop in carrion (Rozkošný et al. 1997).

In this paper, we review 17 known Palearctic and Oriental species belonging to the $F$. postica-group. Based on an extensive literature search and study of dry specimens, a key to the identification of males of known species from these regions is given, and two new species from China are described. One species, F. labidocerca Feng \& Xue, 2006 , is transferred from the $F$. serena-group to the $F$. postica-group and re-described. Illustrations of the male terminalia are included. 


\section{Material and methods}

The morphological terminology used in this paper follows McAlpine (1981), except for the term "postpedicel", which follows Stuckenberg (1999). Absolute measurements in millimeters $(\mathrm{mm})$ are given for body length. The specimens studied for this paper are deposited in the Institute of Entomology, Shenyang Normal University, Shenyang, China (IESNU) and the Shanghai Entomological Museum, Chinese Academy of Science, Shanghai, China (SHEM). Figure of Fannia labidocerca Feng \& Xue, 2006 is from Feng and Xue (2006). Methods for the preparation of terminalia and illustrations follow Zhang et al. (2013).

The following abbreviations are used for characters throughout the text: $a c r=$ acrostichal seta(e), $a d=$ anterodorsal seta(e), $a v=$ anteroventral seta(e), $d=$ dorsal seta(e), $d c=$ dorsocentral seta(e), $i d=$ intra-alar seta(e), $p=$ posterior seta(e), $p d=$ posterodorsal seta(e), pra $=$ prealar seta(e), and $p v=$ posteroventral seta(e).

\section{Taxonomic accounts}

\section{Genus Fannia Robineau-Desvoidy, 1830}

Fannia postica-group: Chillcott 1961: 101, 222; Rozkošný et al. 1997: 48; Wang et al. 2011: 3 .

For a diagnosis of the group see Wang et al. (2011).

Key to males of the known Palearctic and Oriental species in the Fannia postica-group

$1 \quad$ Hind femur with at least $2 a v$ in distal half (Fannia postica-subgroup) ........2

- $\quad$ Hind femur with only 1 av in distal half (Fannia spathiophora-subgroup)...5

2 Pra 1; hind coxa with setulae on posterior surface.... Fannia discoculea Xue

- $\quad$ Pra 2; hind coxa bare on posterior surface.................................................. 3

3 Mid first tarsomere without a basal tooth-like spine on ventral surface; hind femur with 4 to 6 av in distal half; calypters yellow... Fannia postica (Stein)

- $\quad$ Mid first tarsomere with a basal tooth-like spine on ventral surface; hind femur with only $2 a v$ in distal half; calypters blackish ................................ 4

$4 \quad$ Hind femur without distinct $p v$, and with 3 to $5 a v$ in distal half.

Fannia labidocerca Feng \& Xue

- $\quad$ Hind femur with 7 or $8 p v$ in distal half, and with $2 a v$ in distal half

Fannia ringdablana Collin

$5 \quad$ Hind coxa with setulae on posterior surface; $\operatorname{pra} 2$ (rarely 3); frontal setae 7 to 9; mid first tarsomere with a basal tooth-like spine on ventral surface

Fannia coculea Nishida

- Hind coxa bare on posterior surface.......................................................6 
Hind femur without distinct $p v$; haltere brown

Fannia nudifemorata Wang \& Zhang

Hind femur with $p v$

Mid first tarsomere with a weak basal tooth-like spine on ventral surface... 11

1 Syntergite $1+2$ and tergites 3-4 each with a dark median stripe

Fannia aethiops Malloch

Syntergite $1+2$ and tergites 3-4 each with an inverted T-shaped dark mark.... 12 Frons, at its narrowest point, about as wide as anterior ocellus; pra short and weak, the anterior one about $1 / 2$ as long as the length of posterior notopleural seta

Fannia ardua Nishida

Frons, at its narrowest point, slightly wider than the distance between outer margins of posterior ocelli; pra slightly stout, the anterior one about $2 / 3$ as long as the length of posterior notopleural seta.

..Fannia subaethiops Wang \& Zhu, sp. n.

Postocular setae in 2 rows.

14

Postocular setae in one row

15 Acr mainly triserial; mid tibia strongly flattened and with a posteroventral ridge . Acr mainly biserial; mid tibia not strongly flattened and without a posteroventral ridge. Fannia ningxiaensis Wang \& Zhang, sp. $\mathrm{n}$. Scutum entirely black; bacilliform process long and only bent ventrally.....

Fannia umbratica Collin

- Scutum with thin grayish pollinosity; bacilliform process long or short, twisted

16 Hind femur with 10 to 15 stout $p v$; bacilliform process short

Fannia umbrosa (Stein)

Hind femur with 5 stout $p v$; bacilliform process long 
Catalog of known Palearctic and Oriental species in the Fannia postica-group, with redescription of one species and description of two new species

Fannia aethiops Malloch, 1913

Fannia aethiops Malloch, 1913: 628.

Fannia aethiops: Pont 1986: 44; Rozkošný et al. 1997: 23; Xue and Wang 1998: 813;

Wang and Xue 2002: 55; Wu and Wang 2002: 563; Wang et al. 2004: 34; Wang et al. 2006: 555 .

Material examined. China: Jilin: 1 male, Mt. Changbai, $42.33^{\circ} \mathrm{N}, 127.27^{\circ} \mathrm{E}$, 22.VI.1980, Coll. Z.Y. Ma (IESNU). Shanxi: 1 male, Ningwu, Mt. Luya, $38.73^{\circ} \mathrm{N}$, 111.93², 12.VI.1987, Coll. M.F. Wang (IESNU).

Distribution. Nearctic: throughout Canada, USA (Alaska, North Carolina, south to California); Palearctic: China (Jilin, Neimenggu, Shanxi), Sweden.

\section{Fannia ardua Nishida, 1976}

Fannia ardua Nishida, 1976: 135.

Fannia ardua: Pont 1986: 44; Wang and Xue 2002: 55; Wang et al. 2006: 555.

Material examined. China: Jilin: 1 male, Mt. Changbai, $42.33^{\circ} \mathrm{N}, 127.27^{\circ} \mathrm{E}$, 10.VII.1998 (IESNU).

Distribution. Palearctic: China (Jilin), Japan.

\section{Fannia bigelowi Chillcott, 1961}

Fannia bigelowi Chillcott, 1961: 115.

Fannia bigelowi: Pont 1986: 45.

Distribution. Nearctic: Canada, USA (Alaska); Palearctic: Norway.

Fannia coculea Nishida, 1975

Fannia coculea Nishida, 1975: 368.

Fannia cocula: Pont 1977: 448; Xue and Wang 1998: 815; Wang and Xue 2002: 56.

Distribution. Oriental: China (Taiwan). 


\section{Fannia discoculea Xue, 1998}

Fannia discoculea Xue, 1998: 815.

Fannia discoculea: Wang and Xue 2002: 56.

Type specimens examined. Holotype male: China, Xinjiang, Jakesi, $43.82^{\circ} \mathrm{N}$, 81.12ㅌ, 6.VIII.1957, Coll. G. Wang (IESNU).

Distribution. Palearctic: China (Xinjiang).

\section{Fannia gotlandica Ringdahl, 1926}

Fannia gotlandica Ringdahl, 1926: 106.

Fannia gotlandica: Pont 1986: 48; Rozkošný et al. 1997: 39.

Distribution. Palearctic: throughout Europe.

\section{Fannia labidocerca Feng \& Xue, 2006}

Fig. 1

Fannia labidocerca Feng \& Xue, 2006: 217.

Redescription. MALE. Body length $4.8 \mathrm{~mm}$. Eye with short and distant hairs or bare; postocular setae in 2 rows, those of the anterior row sparse and long, curved anteriorly, those of the posterior row short; fronto-orbital plate and parafacial with silvery-white pollinosity; frons at narrowest point slightly wider than the distance between outer margins of posterior ocelli; frontal vitta black, at narrowest point about as wide as fronto-orbital plate; frontal setae 12 , stout, situated on the lower $4 / 5$ of frons, orbital setae absent; parafacial bare, at middle about $1 / 3$ as wide as the width of postpedicel; antenna black, postpedicel about 2.0 to $2.5 \mathrm{x}$ as long as wide, arista ciliated, the longest individual hairs shorter than aristal base; epistoma not projecting beyond vibrissal angle, vibrissal angle behind frontal angle in profile; genal height about $1 / 14$ of eye height; prementum shining, about 3.0x as long as wide; palpus dark brown, claviform, slightly shorter than prementum. Thorax ground-color black, notum with dark brown pollinosity; presutural acr biserial, long, one pair of them slightly stout, only prescutellar pairs stout, $d c 2+3$, ia $0+2$, pra 2 , about $2 / 5$ of length of posterior notopleural seta; notopleuron bare; basisternum, proepisternum, anepimeron, meron and katepimeron bare; katepisternal setae $1+1$, katepisternum without a ventral spine; spiracles brown; calypters mostly brown or brownish, brownish on the outer margin, the lower one small and tongue-like, about $1 / 2$ as long as the upper one. Wing brownish; veins and wing-base yellow; basicosta brownish-yellow; costal spine inconspicuous; node of Rs bare on ventral and dorsal surfaces; vein $\mathrm{M}_{1+2}$ straight, parallel to vein $\mathrm{R}_{4+5}$ distally; crossveins not clouded; haltere 

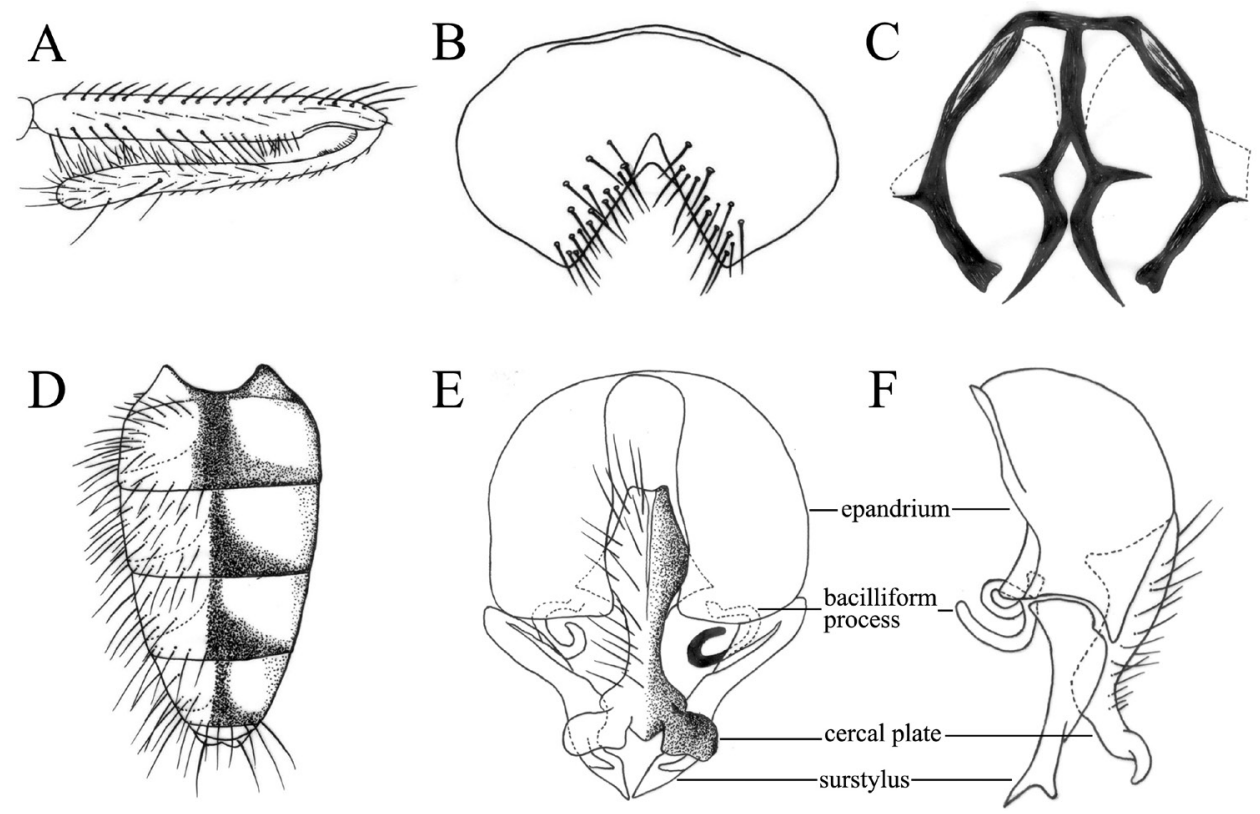

Figure I. Fannia labidocerca Feng \& Xue, 2006, male, holotype: (A-F in figure 1 without scale are all from Feng \& Xue 2006, specimen from Sichuan, deposited in IESNU). A Mid leg, anterior view B Sternite 5 , ventral view $\mathbf{C}$ Sternite 9, ventral view. D. Abdomen, dorsal view $\mathbf{E}$ Terminalia, ventral view $\mathbf{F}$ Terminalia, lateral view.

brown in basal part, yellowish at middle and dark brown in distal part. Legs entirely black, sometimes dark brown or brown; fore tibia without $p$; mid coxa without any hook-like spine or spine-like seta; mid femur concave on ventral surface in apical part, becoming swollen from distal $1 / 3$ towards basal part, with a row of $a v$, stout in basal part, becoming shorter and denser in distal $1 / 4$, with a cluster of spine-like setae in distal $1 / 3$, a complete row of $a d$, slightly short (Fig. 1A), with a complete row of slender $p$, slightly situated on the posteroventral surface, with a row of $p v$ in basal $4 / 5$, and with a row of setulae at middle towards distal 1/4; mid tibia slightly swollen towards apex, in distal half with one $a d$, one preapical $d$, one $p d$, and with numerous slender setulae on ventral surface, most of the setulae longer than mid tibial width in distal part (Fig. 1A); mid first tarsomere with a basal tooth-like spine on ventral surface; hind coxa bare on posterior surface; hind femur with 3 stout $a v$ in distal $1 / 3$, without $p v$; hind tibia with one $a v$, one $a d$ and one median $d$. Abdomen long and flattened (Fig. 1D), groundcolor black, with thin gray pollinosity; syntergite $1+2$ and tergites $3-5$ each with one dark median triangular vitta (Fig. 1D); sternite 1 with 4 long lateral marginal setae; for morphology of sternites 5 and 9 and terminalia, see Fig. 1B, C, E, F.

FEMALE. Unknown.

Remarks. Feng and Xue (2006) placed F. labidocerca into the F. serena-subgroup of the F. serena-group while recording the species from the Mt. Emei Region, Sichuan, China. However, this species should be placed into the $F$. postica-subgroup by sharing 
the following morphological characters with all other species of the subgroup: mid first tarsomere with a distinct basal tooth-like spine on ventral surface; lower calypter short, tongue-like (Fig. 1E, F).

Type specimens examined. Holotype male: China, Sichuan, Emeishan, Mt. Emei, $29.59^{\circ} \mathrm{N}, 103.30^{\circ} \mathrm{E}, 3099 \mathrm{~m}, 22$. VI.1984, Coll. Y. Feng (IESNU). Paratypes: 1 male, China, Sichuan, Yaan, Hanyuan, Mt. Jiaoding, 3550 m, 8.VII.1987, Coll. Y. Feng (IESNU); 1 male, China, Yunnan, Lushui, Pianma, Mt. Gaoligong, 2400 m, 24.VI.2010, Coll. Y.Y. Zhou (IESNU).

Distribution. Oriental: China (Yunnan); Palearctic: China (Shaanxi, Sichuan).

\section{Fannia ningxiaensis Wang \& Zhang, sp. $\mathrm{n}$.}

http://zoobank.org/C3089E00-6329-40D5-B852-ECBF3D1F70BB

Fig. 2

Description. MALE. Body length $4.0 \mathrm{~mm}$. Eye bare; postocular setae in one row, slender and curved anteriorly, occipital setae situated behind the postocular setae on vertex and in one row; fronto-orbital plate and parafacial with grayish-silvery pollinosity; frons at narrowest point slightly narrower than the distance between outer margins of posterior ocelli, about $2 / 3$ as wide as postpedicel; frontal vitta black, linear at narrowest point; frontal setae 7 to 9 , stout, nearly reaching ocellar triangle, the gaps between them without setulae; orbital setae absent; parafacial bare and narrow, at middle about 2/5 of width of postpedicel; antenna black, postpedicel about $1.5 \mathrm{x}$ as long as wide, arista black and ciliated, slightly swollen in basal part, the longest individual hairs shorter than aristal base; epistoma not projecting beyond vibrissal angle, vibrissal angle behind frontal angle in profile; subvibrissal setulae in one row, lateral of it with 2 or 3 fine setae; gena and genal dilation with black setulae, upper margin of gena without upcurved setae; prementum with thin grayish pollinosity, slightly shining, about $2.3 \mathrm{x}$ as long as wide; palpus black, claviform, about as long as prementum. Thorax ground-color black, notum with thin dark brown pollinosity, without a distinct vitta; presutural acr biserial, slightly stout, prescutellar pairs stout, the distance between the 2 rows of acr narrower than the distance between rows of $a c r$ and $d c ; d c 2+3$, ia $0+2$, pra 2 , the anterior one about $3 / 5$ as long as posterior notopleural seta; notopleuron bare; proepisternal setae 2 , proepimeral seta 1 , with about 10 slender setulae around it; basisternum, proepisternum, anepimeron, meron and katepimeron bare; katepisternal setae $1+1$, katepisternum without a ventral spine, with only some fine and curved setae; anterior spiracle brown, posterior spiracle dark brown; calypters brownish with yellow-brownish margin, the lower calypter slightly smaller than the upper one and not projecting beyond the upper one. Wing brownish; veins brown; wing-base of similar color to other parts of wing; tegula black; basicosta brown; costal spine inconspicuous; node of Rs bare on ventral and dorsal surfaces; vein $R_{4+5}$ straight, parallel to vein $M_{1+2}$ distally; crossveins not distinctly clouded; haltere brownish-yellow. Legs entirely black; fore coxa without a spine on anterior ventral surface; fore femur with a complete row of $p v$; fore tibia 

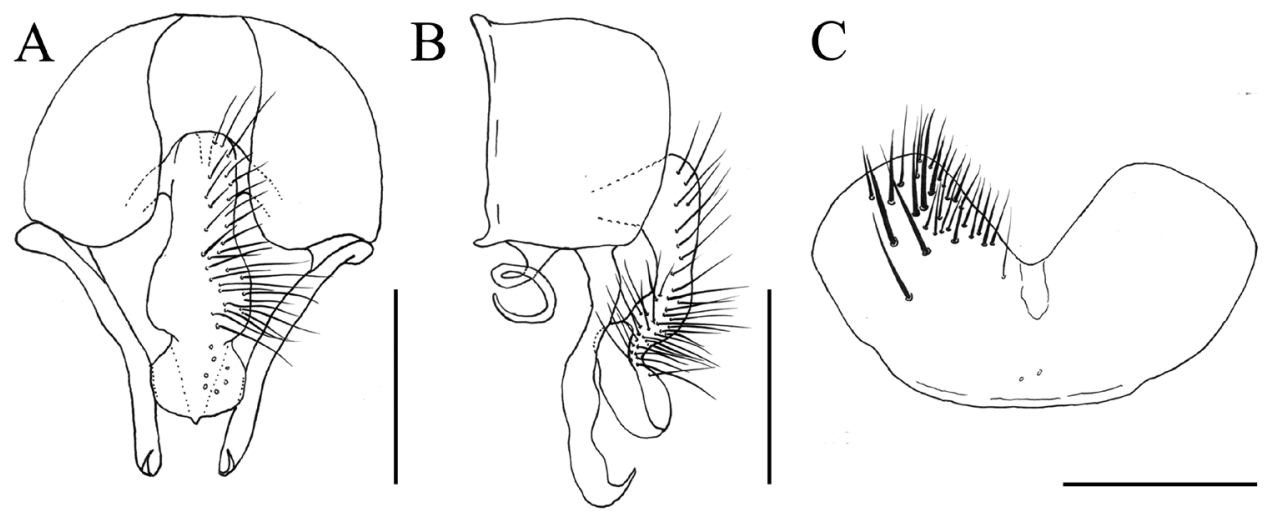

Figure 2. Fannia ningxiaensis Wang \& Zhang, sp. n., male, holotype: (specimen from Ningxia, deposited in IESNU). A. Terminalia, ventral view B Terminalia, lateral view C Sternite 5, ventral view. Scale for $\mathbf{A}-\mathbf{C}=0.25 \mathrm{~mm}$.

without $a d$ and median $p$, and with only one stout preapical $d$; fore first tarsomere with several longish basal setae on ventral surface; mid coxa without a hook-like spine or spine-like seta; mid femur with 6 to 8 stout $a v$ in basal part, becoming gradually shorter and denser towards apex, with a gap in preapical part, 2 to 4 comb-like setae in distal part, and with a row of stout $p v$, slightly biserial in median part, with a gap in preapical part, with 4 or 5 comb-like setae in distal part, and with a row of slender $p$; mid tibia slightly swollen in distal half, with one $a d$ and one $p d$ in distal half, and with numerous slender setulae on ventral surface, the longest one about $3 / 4$ of mid tibial width in distal part; mid first tarsomere without a basal tooth-like spine on ventral surface, and with only short basal clustered setulae; hind coxa bare on posterior surface; hind femur with only one stout $a v$ in preapical part, with 8 to 10 stout $p v$ in distal half; hind tibia with one $a v$, one $a d$, and one median $d$, and with 8 or 9 slightly erect median setae on posterior surface. Abdomen oval and flattened, ground-color black, with dense grayish-blue pollinosity; syntergite $1+2$ and tergites 3-4 each with one dark broad median triangular vitta, tergite 5 with one dark median stripe in basal part; sternite 1 with setulae, sternite 5 broad (Fig. 2C); cercal plate longish, from ventral view, apex of cercal plate projecting, large and rounded, as broad as middle part of cercal plate and slightly broader than the basal part (Fig. 2A); bacilliform process twisted (Fig. 2B); surstylus slender, hook-like at apex and pointed posteriorly (Fig. 2A, B).

FEMALE. Unknown.

Remarks. The new species is attributed to the spathiophora-subgroup of the posti$c a$-group. It can be distinguished from a similar European species, Fannia stigi Rognes, 1982, by the following character states: mid first tarsomere with only short basal clustered setulae on ventral surface; hind femur with 8 to 10 stout $p v$ in distal half; abdominal syntergite $1+2$ and tergites 3-4 each with one dark broad median triangular vitta; apex of cercal plate projecting, large and rounded in ventral view (Fig. 2A); bacilliform process twisted (Fig. 2B), while F. stigi Rognes mid first tarsomere with a basal 
tooth-like spine; hind femur with 4 or 5 stout $p v$ in distal half; abdominal syntergite $1+2$ and tergites 3-4 each with a dark median stripe; apex of ceral plate not projecting, half round in ventral view; bacilliform process not twisted.

Etymology. The specific name is derived from name of the type locality, Ningxia.

Types material. Holotype male: China, Ningxia, Guyuan, Jingyuan, Dongshanpo, 2200 m, 27.VI.2008, Coll. M.F. Wang (IESNU). Paratype: 1 male, China, Ningxia, Guyuan, Jingyuan, Dongshanpo, 2000 m, 27.VI.2008, Coll. M.F. Wang (IESNU).

Distribution. Palearctic: China (Ningxia).

\section{Fannia nudifemorata Wang \& Zhang, 2011}

Fannia nudifemorata Wang \& Zhang, 2011: 12.

Type specimens examined. Holotype male: China, Yunnan, Yulongxueshan, $27.09^{\circ} \mathrm{N}, 100.25^{\circ} \mathrm{E}, 3200 \mathrm{~m}, 24 . V .2007$, Coll. W.X. Dong (IESNU). Paratype: 1 male, same locality and time, Coll. S.C. Bai (IESNU).

Distribution. Oriental: China (Yunnan).

\section{Fannia postica (Stein, 1895)}

Fannia postica Stein, 1895: 89.

Fannia postica: Hennig 1955: 24; Chillcott 1961: 103; Pont 1986: 53; Rozkošný et al. 1997: 27; Xue and Wang 1998: 819; Wang and Xue 2002: 57; Wang et al. 2006: 555.

Material examined. China: Heilongjiang: 2 male, Xilinji, $53.48^{\circ} \mathrm{N}, 122.37^{\circ} \mathrm{E}$, 19.VI.1986, Coll. C.Y. Cui (IESNU).

Distribution. Nearctic: throughout North America; Palearctic: Austria, Belgium, Bulgaria, China (Heilongjiang), Czech Republic, Denmark, Finland, former Yugoslavia, France, Germany, Iceland, Ireland, Italy, Luxembourg, Norway, Poland, Romania, Slovakia, Spain, Sweden, Switzerland, United Kingdom (England).

\section{Fannia ringdablana Collin, 1939}

Fannia ringdablana Collin, 1939: 143.

Fannia ringdablana: Hennig 1955: 20; Pont 1977: 449; Pont 1986: 54; Fan 1992: 216; Wang and Wu 1996: 66; Rozkošný et al. 1997: 22; Xue and Wang 1998: 815; Wang and Xue 2002: 57; Wu and Wang 2002: 563; Wang et al. 2004: 34; Wang et al. 2006: 555.

Material examined. China: Jilin: 2 male, Mt. Changbai, Xiaotianchi, $42.58^{\circ} \mathrm{N}, 128.30^{\circ} \mathrm{E}$, 25.VII.1982, Coll. L.Y. Gao (IESNU); 2 male, Mt. Changbai, $42.33^{\circ} \mathrm{N}, 127.27^{\circ} \mathrm{E}$, 
18.VII.1988, [collector unknown]. Shanxi: 1 male, Ningwu, Mt. Luya, $38.73^{\circ} \mathrm{N}$, $111.93^{\circ} \mathrm{E}, 12$. VI.1987, Coll. M.F. Wang (IESNU). Sichuan: 2 male, Jiuzaigou, $33.26^{\circ} \mathrm{N}$, $103.91^{\circ} \mathrm{E}, 2800 \mathrm{~m}, 1 . \mathrm{VI} .2006$, Coll. Y. Zhu (IESNU); 3 male, same locality, 2.VI.2006, Coll. D. Jing (IESNU); 9 male, same locality, 3.VI.2006, Coll. D. Wang (IESNU); 1 male, Daocheng, Kasi, $29.04^{\circ} \mathrm{N}, 100.31^{\circ} \mathrm{E}, 2750-3000$ m, 12.VII.2006, Coll. C.T. Zhang (IESNU). Yunnan: 1 male, Deqin, Mt. Meili, $28.49^{\circ} \mathrm{N}, 98.93^{\circ} \mathrm{E}, 4000-4200 \mathrm{~m}$, 2.VII.2006, Coll. Y. Wang (IESNU); 1 male, Xianggelila, Bitahai, $27.80^{\circ} \mathrm{N}, 99.90^{\circ} \mathrm{E}$, 3700 m, 2.VII.2006, Coll. B.F. Wang (IESNU); 5 male, same locality and time, Coll. L. Chang (IESNU); 5 male, same locality and time, Coll. M.F. Wang (IESNU).

Distribution. Oriental: China (Taiwan, Yunnan); Palearctic: China (Jilin, Shanxi, Sichuan), Japan, Sweden, United Kingdom.

\section{Fannia spathiophora Malloch, 1918}

Fannia spathiophora Malloch, 1918: 294.

Fannia spathiophora: Chillcott 1961: 112; Wang and Wu 1996: 66; Rozkošný et al. 1997: 23; Xue and Wang 1998: 815; Wang and Xue 2002: 57; Wu and Wang 2002: 563; Wang et al. 2004: 34; Wang et al. 2006: 556.

Material examined. China: Heilongjiang: 1 male, Wuying, $48.11^{\circ} \mathrm{N}, 129.24^{\circ} \mathrm{E}$, 16.VII.1977, Coll.C.Y.Cui(IESNU); 1 male, Guyuan, $50.58^{\circ} \mathrm{N}, 123.70^{\circ} \mathrm{E}, 26 . V I .1980$, Coll. C.Y. Cui (IESNU); 1 male, Bizhou, $51.94^{\circ} \mathrm{N}, 124.60^{\circ} \mathrm{E}, 13 . \mathrm{VII} .1980$ [collector unknown] (IESNU). Jilin: 1 male, Baihe, $42.58^{\circ} \mathrm{N}, 128.04^{\circ} \mathrm{E}, 20 . \mathrm{VI} .1980$, Coll. Z.Y. Ma (IESNU); 1 male, Mt. Changbai, $42.33^{\circ} \mathrm{N}, 127.27^{\circ} \mathrm{E}, 19 . \mathrm{VII} .1986$ [collector unknown] (IESNU); 1 male, Mt. Changbai, $42.33^{\circ} \mathrm{N}, 127.27^{\circ} \mathrm{E}, 15 . \mathrm{VII} .1990$ [collector unknown] (IESNU). Liaoning: 2 male, Xinbin, Gangshan, $41.72^{\circ} \mathrm{N}, 125.02^{\circ} \mathrm{E}$, -.VI.1981, Coll. Z.Y. Ma (IESNU); 1 male, same locality, 08.IX.1990, [collector unknown] (IESNU); 2 male, Benxi, Yanghugou, $41.30^{\circ} \mathrm{N}, 123.73^{\circ} \mathrm{E}, 01 . \mathrm{VII} .1993$, Coll. Y.S. Cui (IESNU); 1 male, same locality, 01.VII.1993, Coll. C.T. Zhang (IESNU); 1 male, Huanren, $41.27^{\circ} \mathrm{N}, 125.35^{\circ} \mathrm{E}, 09 . \mathrm{VI} .1994$, Coll. D. Wei (IESNU); 3 male, Qianshan, $41.03^{\circ} \mathrm{N}, 123.13^{\circ} \mathrm{E}, 25$. VI.2007, Coll. M.F. Wang (IESNU). Shanxi: 1 male, Hunyuan, $39.70^{\circ} \mathrm{N}, 113.68^{\circ} \mathrm{E}, 12 . \mathrm{VII} .1985$, Coll. M.F. Wang (IESNU).

Distribution. Nearctic: Canada (Labrador, Northwest Territories, Ontario), USA (Alaska, south to Arizona \& New Mexico, Minnesota); Palearctic: China (Hebei, Heilongjiang, Jilin, Liaoning, Shanxi), throughout Europe, Japan.

\section{Fannia slovaca Gregor \& Rozkošný, 2005}

Fannia slovaca Gregor \& Rozkošný, 2005: 519.

Distribution. Palearctic: Slovakia. 


\section{Fannia stigi Rognes, 1982}

Fannia stigi Rognes, 1982: 325.

Fannia stigi: Wang, Li and Zhang 2011: 15.

Fannia tigripeda: Xue, Wang and Li 2001: 225-226; Wang and Xue 2002: 57; Su and Wang 2004: 112.

Material examined. China: Jilin: Mt. Changbai, $42.33^{\circ} \mathrm{N}, 127.27^{\circ} \mathrm{E}, 1700 \mathrm{~m}$, 28.VI.1997, Coll. W.Q. Xue (IESNU). Shanxi: 1 male, Ningwu, $38.73^{\circ} \mathrm{N}, 111.93^{\circ} \mathrm{E}$, 07.VI.1982, Coll. M.F. Wang (IESNU).

Distribution. Palearctic: China (Jilin, Shanxi), Norway, Sweden.

\section{Fannia subaethiops Wang \& Zhu, sp. n.}

http://zoobank.org/A9405B63-59AD-4D73-829F-F0364A86A69A

Fig. 3

Description. MALE. Body length $5.0 \mathrm{~mm}$. Eye bare; upper inner facets larger than the remaining facets; postocular setae in one row, short and neatly arranged, occipital setae absent; fronto-orbital plate and parafacial with grayish-silvery pollinosity; frons at narrowest point slightly wider than the distance between outer margins of posterior ocelli, about as wide as postpedicel; frontal vitta black, with grayish-silvery pollinosity, at narrowest point about as wide as fronto-orbital plate; frontal setae 5, stout, nearly reaching ocellar triangle, the gaps between them without setulae, orbital setae absent; parafacial bare, at middle about $1 / 2$ as wide as postpedicel; antenna black, postpedicel about $1.5 \mathrm{x}$ as long as wide, arista ciliated, slightly swollen in basal part, the longest individual hairs shorter than aristal base; epistoma not projecting beyond vibrissal angle, vibrissal angle behind frontal angle in profile; subvibrissal setulae in one row, lateral of it with several setae; gena and genal dilation with black setulae, upper margin of gena without upcurved setae; prementum shining, without distinct pollinosity, about $2.0 \mathrm{x}$ as long as wide; palpus black, claviform, slightly longer than prementum. Thorax ground-color black, notum with dark brown pollinosity, without a distinct vitta; presutural acr biserial, slightly stout, only prescutellar pairs stout, the distance between 2 rows of acr narrower than the distance between rows of acr and $d c$; $d c 2+3$, ia $0+2$, pra 2 , the anterior one stout, about $2 / 3$ as the length of posterior notopleural seta; notopleuron bare; proepisternal setae 2 , proepimeral seta 1 , lower part of proepimeral seta with one short setula; basisternum, proepisternum, anepimeron, meron and katepimeron bare; katepisternal setae 1+1, katepisternum without a ventral spine; spiracles brown; calypters brownish-yellow, the lower one slightly projecting beyond the upper one. Wing brownish; veins dark brown; wingbase of same color as other parts of wing; tegula dark brown; basicosta brownishyellow; costal spine conspicuous, about $2 / 3$ of the length of crossvein $r-m$; node of Rs 

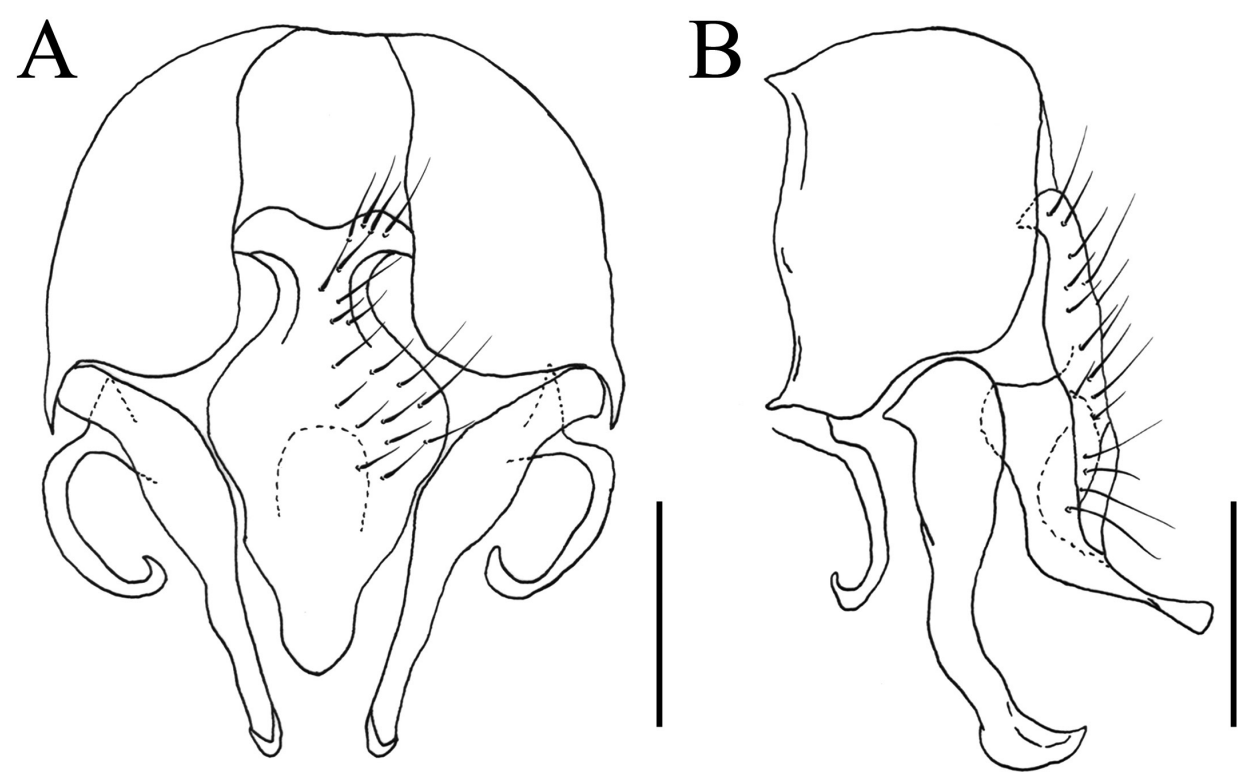

Figure 3. Fannia subaethiops Wang \& Zhu, sp. n., male, holotype: (specimen from Heilongjiang, deposited in SHEM). A Terminalia, ventral view B Terminalia, lateral view. Scale for $\mathbf{A}-\mathbf{B}=0.25 \mathrm{~mm}$.

bare on ventral and dorsal surfaces; vein $\mathrm{R}_{4+5}$ straight, veins $\mathrm{M}_{1+2}$ and $\mathrm{R}_{4+5}$ converging distally; crossveins not clouded; haltere brown. Legs entirely black, except knees yellow; fore coxa without a anterior spine on ventral surface; fore femur with a stout row of $p v$; fore tibia without $a d$ and median $p$, with only one $d$ and one $v$ in apical part; fore first tarsomere with few longish basal setae on ventral surface; mid coxa without a hook-like spine or spine-like seta; mid femur with a row of stout and sparse $a v$ in basal half, becoming shorter and denser towards apex, with a gap in preapical part, 2 or 3 comb-like setae in distal part, a complete row of stout $p v$, slightly biserial in median part, and a row of slender $p$; mid tibia slightly narrowing in basal half, gradually swollen towards apex, about 2.0x as wide in distal part as wide in basal part, with one $a d$ and one $p d$ in distal half, and with numerous slender setulae on ventral surface, the longest one about $3 / 4$ as long as mid tibial width in distal part; mid first tarsomere without a basal tooth-like spine on ventral surface, with only short basal clustered setulae; hind coxa bare on posterior surface; hind femur with only one stout $a v$ and 3 or $4 p v$ in preapical part; hind tibia with one $a v$, one $a d$ and one $d$. Abdomen long and flattened, ground-color black, with grayish-brown pollinosity; syntergite $1+2$ and tergites 3-4 each with an inverted T-shaped dark mark, each tergite with stout lateral marginal setae; sternite 1 broad, with 4 long setae on each lateral margin, sternites 2 to 4 narrow, with long setulae, sternite 5 with slightly dense setae in posterior margin; cercal plate longish, from ventral view, cercal plate slightly indented in each lateral margin, middle part of cercal plate strongly broader than the apex and the basal part 
(Fig. 3A); bacilliform process curved (Fig. 3A, B); surstylus slender, curved at apex and pointed posteriorly (Fig. 3A, B).

FEMALE. Unknown.

Remarks. The new taxon is similar to the holarctic species F. aethiops Malloch, 1913 but differs from it for the following character states: frontal setae only 5; anterior pra about $2 / 3$ as long as posterior notopleural seta; sternite 1 with 4 long setae on each lateral margin; in ventral view, cercal plate broadest in median part, slightly indented in each lateral margin (Fig. 3A); bacilliform process curved (Fig. 3A \& B), while $F$. aethiops Malloch frontal setae 9; anterior pra about $1 / 2$ as long as posterior notopleural seta; sternite 1 with 1-2 long setae on each lateral margin; in ventral view, cercal plate not indented in each lateral margin; bacilliform process not curved.

Etymology. This specific name refers to the similarity between the new species and F. aethiops Malloch.

Types material. Holotype male: China, Heilongjiang, Yichun, Wuying, 3.V.1975, Coll. S.Y. Fang (SHEM).

Distribution. Palearctic: China (Heilongjiang).

\section{Fannia umbratica Collin, 1939}

Fannia umbratica Collin, 1939: 144.

Fannia umbratica: Hennig 1955: 90; Pont 1986: 57; Rozkošný et al. 1997: 47.

Distribution. Palearctic: throughout Europe.

\section{Fannia umbrosa (Stein, 1895)}

Fannia umbrosa (Stein, 1895): 75.

Fannia umbrosa: Hennig 1955: 90; Pont 1986: 57; Rozkošný et al. 1997: 47.

Distribution. Palearctic: throughout Europe.

\section{Acknowledgments}

Sincere thanks to Dr. Adrian C. Pont (Oxford University Museum of Natural History, Oxford, U.K.), Dr. Rudolf Rozkošný (Faculty of Science, Masaryk University, Brno, Czech Republic), and Dr. Kazumi Nishida (Kobe Institute of Health, Kobe, Japan) for giving us invaluable help for many years. This study was supported by the Director Foundation of the National Nature Science Foundation of China (No. 31272347 , No. 31071957), and the Director Fund of Ecology and Environment Research Centre, Shenyang Normal University (No. EERC-K-201401). 


\section{References}

Chillcott JG (1961) A revision of the Nearctic species of Fanniinae (Diptera: Muscidae). Canadian Entomologist Supplement 14(1960): 1-295. doi: 10.4039/entm9214fv

Collin JE (1939) On various new or little known British Diptera, including several species bred from the nests of birds and mammals (Part.). Entomologist's Monthly Magazine 75: 134-144.

D’Assis-Fonseca ECM (1968) Diptera Cyclorrhapha Calyptrata. Section (b) Muscidae. Handbook for the Identification of British Insects 10 4(b): 1-119.

Fan ZD (1992) Key to the common flies of China, second edition. Science Press, Beijing, 992 pp. [In Chinese]

Feng Y, Xue WQ (2006) Six new species of the genus Fannia R.-D. from Sichuan, China (Diptera, Fanniidae). Acta Zootaxonomica Sinica 31(1): 215-223. [In Chinese with English abstract]

Gregor F, Rozkošný R (2005) A new species of Fannia (Diptera: Fanniidae) from central Europe. Biologia Bratislava 60(5): 519-522.

Hennig W (1955) Muscidae. In: Lindner E (Ed.) Die Fliegen der Palaearktischen Region, 63b (part). Schweizerbart, Stuttgart, 1-99.

Malloch JR (1913) Notes on some American Diptera of the genus Fannia, with descriptions of new species. Proceedings of the United States National Museum 44: 621-631. doi: 10.5479/si.00963801.44-1972.621

Malloch JR (1918) Diptera from the Southwestern United States, Paper IV, Anthomyiidae. Transactions of the American Entomological Society 44: 263-319.

McAlpine JF (1981) Morphology and terminology - adults. In: McAlpine JF, Peterson BV, Shewell GE, Teskey HJ, Vockeroth JR, Wood DM (Eds) Manual of Nearctic Diptera, Volume I. Research Branch, Agriculture Canada Monograph, 27, Ottawa, 9-63.

Nishida K (1975) Six new and one newly recorded species of the genus Fannia (Diptera: Muscidae) from Taiwan, with a key to species. Japanese Journal of Entomology 43(3): 364-380.

Nishida K (1976) Studies on the species of Fanniinae (Diptera: Muscidae) from Japan. IV. Five new and two newly recorded species of genus Fannia from Japan. Japanese Journal of Sanitary Zoology 27(2): 133-143.

Pont AC (1977) Family Fanniidae. In: Delfinado MD, Hardy DE (Eds) A catalog of Diptera of the Oriental Region, Volume III. Suborder Cyclorrhapha (excluding Division Aschiza). University of Hawaii, Honolulu, 447-450.

Pont AC (1986) Family Fanniidae. In: Soós Á, Papp L (Eds) Catalogue of Palearctic Diptera. Volume XI. Scathophagidae-Hypodermatidae. Akadémiai Kiadó, Budapest, 41-57.

Ringdahl O (1926) Neue nordische Musciden nebst Berichtigung und Namensänderungen. Entomologisk Tidskrift 47: 101-118

Rognes K (1982) Fannia stigi n.sp. from Scandinavia (Diprera: Fanniidae). Entomologica Scandinavica 13: 325-330. doi: 10.1163/187631282X00390

Rozkošný R, Gregor F, Pont AC (1997) The European Fanniidae (Diptera). Acta Scientiarum Naturalium Academiae Scientiarum Bohemicae-Brno 31: 1-80.

Stein P (1895) Die Anthomyidengruppe Homalomyia nebst ihren Gattungen und Arten. Berliner Entomologische Zeitschrift 40(1): 81-141. doi: 10.1002/mmnd.18950400104 
Stuckenberg BR (1999) Antennal evolution in the Brachycera (Diptera), with a reassessment of terminology to the flagellum. Studia Dipterologica 6: 33-48.

Su LX, Wang MF (2004) Studies on classification of the genus Fannia in China (Diptera: Fanniidae). Chinese Journal of Vector Biology and Control 15(2): 110-112. [In Chinese with English abstract]

Wang BF, Wang MF, Xue WQ (2006) Studies on fauna of Fanniidae in Dongbei Region of China. Chinese Journal of Pest Control 22(8): 554-557. [In Chinese with English abstract]

Wang MF, Li K, Zhang D (2011) Taxonomic review of the postica-group of Fannia RobineauDesvoidy (Diptera, Fanniidae) from China, with the description of one new species. Zookeys 112: 1-19. doi: 10.3897/zookeys.112.947

Wang MF, Wu YX (1996) Taxonomic study of Fanniidae in Shanxi (Diptera). Shanxi Journal of Preventive Medicine 5(2): 65-67. [In Chinese]

Wang MF, Xue WQ (2002) Taxonomic study on Fanniidae of China (Diptera: Cyclorrhapha). In: Li DM, Kang L, Wu JW (Eds) Innovation and Development in Entomology. Science and Technology Press of China, Beijing, 54-59. [In Chinese]

Wang MF, Xue WQ, Cao XF (2004) Studies on the Family Fanniidae from the Subregion Loess Plateau of China (Diptera: Cyclorrhapha). Chinese Journal of Vector Biology and Control 15(1): 33-35. [In Chinese with English abstract]

Wu YX, Wang MF (2002) Studies on the family Fanniidae from Shanxi (Diptera: Cyclorrhapha). In: Li DM, Kang L, Wu JW (Eds) Innovation and Development in Entomology. Science and Technology Press of China, Beijing, 562-564. [In Chinese]

Xue WQ, Wang MF (1998) Fanniidae. In: Xue WQ, Chao CM (Eds) Flies of China. Volume I. Liaoning Science and Technology Press, Shenyang, 809-835. [In Chinese with English abstract]

Xue WQ, Wang MF, Li FH (2001) The descriptions of two new species of the genus Fannia R.-D. from China (Diptera: Fanniidae). Acta Zootaxonomica Sinica 26(2): 225-228. [In Chinese with English abstract]

Zhang D, Zhang M, Pape T, Gu CW, Wu W (2013) Sarcophaga (Hoa) flexuosa Ho (Diptera: Sarcophagidae): association of sexes using morphological and molecular approaches, and a redefinition of Hoa Rohdendorf. Zootaxa 3670(1): 71-79. 